\title{
Cervical cancer in Finland and South Wales: implications of end results data on the natural history
}

\author{
MA TTI HAKA MA \\ From the Department of Public Health, University of Tampere, Tampere, and the Finnish Cancer Registry,
Helsinki
}

ROBERT WEST

From the Department of Community Medicine, Welsh National School of Medicine, Cardiff

\begin{abstract}
SUMMARY The population-based cancer registry data on patients with cervical cancer in Finland and South Wales in 1960-69 were analysed for survival. Patients with carcinoma-in-situ experienced essentially the normal life expectancy. Those with invasive carcinoma experienced $75 \%$ of normal post-registration life expectancy in Finland but only $45 \%$ in South Wales. The difference was due to higher frequency and to better survival of patients with localised carcinoma in Finland, which was attributed to the fact that in Wales the mean age of the population is higher than that in Finland, and also to the longer delay in Wales from first symptoms to diagnosis among women with localised cancer. The differences in mean age by clinical stage and in survival combined with the duration of symptoms support the hypothesis that speed of tumour growth is a major determinant of clinical stage at diagnosis.
\end{abstract}

Early attempts to describe the natural history of cervical cancer were based on the assumption that the disease has a slow and regular progression from normal epithelium to invasive carcinoma over a period of several years. ${ }^{1}$ The correlation between age at diagnosis and clinical stage was one of the strongest indications in favour of this assumption. These views were largely accepted and today mass screening programmes are based on this basic model of the natural history of cervical cancer. Another interpretation of the epidemiological observations was given by Ashley ${ }^{2}$ who proposed that there are two types of cervical cancer, one slow growing with relatively good prognosis and occurring in younger women, the other fast growing, less susceptible to cure, and occurring in older women. The purpose of this paper is to make inferences on the natural history of cervical cancer on the basis of the clinical course of the disease, using observations of incidence, of delay in the start of treatment, and of long-term survival. The empirical material originates from Finland and from Wales, representing areas where patients with cervical cancer have good and poor prognosis respectively. ${ }^{3}$

\section{Method}

We have analysed the patients with cervical cancer in Finland and South Wales notified to the population-based cancer registries in each area during the 10 years $1960-69$.

Survival of the patients was estimated by the life table method," which utilises the total survival information irrespective of whether the patients are alive or dead at the end of the study. The actuarial rates describe the mortality due to all causes of death. Observed survival rates were adjusted for mortality due to causes other than cervical cancer by the use of relative survival rates. ${ }^{5}$ Furthermore, from the actuarial survival rates and population life tables, we deduced the estimated expectation of life and the estimated length of life loss due to cervical cancer by extent of the disease. ${ }^{67}$

The Finnish Cancer Registry covers the whole population of Finland (2.4 million women in 1971) and was started in $1953 .^{8}$ All known cases of invasive cervical cancer and of carcinoma-in-situ are registered and classified as (i) carcinoma-in-situ (ii) localised invasive or (iii) non-localised invasive. The definition 
Table 1 Number and percentage of cases of cervical cancer by extent of the disease

\begin{tabular}{|c|c|c|c|c|c|c|}
\hline \multirow[b]{2}{*}{ Extent } & \multicolumn{3}{|c|}{ Finland } & \multicolumn{3}{|c|}{ South Wales } \\
\hline & No. & $\%$ & & No. & $\%$ & \\
\hline $\begin{array}{l}\text { Carcinoma-in-situ } \\
\text { Localised invasive } \\
\text { Non-localised } \\
\text { All (extent known) } \\
\text { Extent unknown }\end{array}$ & $\begin{array}{r}1961 \\
2787 \\
980\end{array}$ & $\begin{array}{l}(34) \\
(49) \\
(17) \\
5728 \\
265\end{array}$ & $(100 \%)$ & $\begin{array}{r}483 \\
369 \\
1056\end{array}$ & $\begin{array}{r}(25) \\
(19) \\
(55) \\
1908 \\
648\end{array}$ & $(100 \%)$ \\
\hline Total registered & 5993 & & & 2556 & & \\
\hline
\end{tabular}

of a localised cancer includes patients with primary tumour confined to the site of the origin and with no metastatic spread (this corresponds to clinical stage I in the F.I.G.O. or TNM classifications). The stage at diagnosis is unknown in fewer than five per cent of patients registered. The follow-up of the patients is until death and all death certificates issued in Finland are matched annually against the files of the registry.

The cancer registry in South Wales is one of the regional registries which together cover the entire population of England, Wales, and Scotland. The population covered in South Wales comprises an estimated $1 \cdot 1$ million women (1971 census) and patients diagnosed as cancer sufferers and resident within the designated area are registered wherever in the United Kingdom treatment was initiated. ${ }^{9}$ Classification of stage is made according to the recommendations of F.I.G.O. These are: stage I tumour strictly limited to the cervix; stage II extending beyond the cervix but not to the pelvic wall; stage III extending to the pelvic wall; and stage IV carcinoma extending beyond the true pelvis and involving the bladder or rectum. A high proportion of patients $(26 \%$ of those registered during the years 1960-69 inclusive) were recorded as 'stage not known'. Annual follow-up was undertaken by regional registries until 1971, but since 1972 the South Wales registry has relied on notification of death by the Office of Population Censuses and Surveys.

The first course of treatment was recorded by both registries and patients were classified into the following groups: (i) surgery (ii) radiotherapy (iii) combined surgery and radiotherapy and (iv) other or no known therapy. The patients were followed up until the end of 1975.

Duration of symptoms was not included on the magnetic tapes of the registry material so a sample of about 100 records of patients with cervical cancer was drawn from the original files of the cancer registries in both countries.

\section{Results}

The total numbers of patients with cervical cancer diagnosed in 1960-69 were 5993 in Finland and 2556 in South Wales (Table 1). Nine hundred and thirteen patients, the extent of whose disease was not known by the registries, have been excluded from this analysis. Approximately one-third of the cases were preclinical at the time of diagnosis-34\% in Finland and $25 \%$ in South Wales. However, there were big differences between the countries by stage of clinical disease. In Finland $74 \%$ of patients with invasive carcinoma of known stage were diagnosed as localised, whereas in South Wales only $26 \%$ of patients with invasive carcinoma of known stage were classified as localised (stage I).

The overall five-year survival rates were $70 \%$ in Finland and 54\% in South Wales (Table 2). However, the simple observed five-year survival rates showed very little difference between the two countries when the extent of the disease, or the clinical staging, was taken into account. Relative survival curves for carcinoma-in-situ, localised, and non-localised carcinomas to 10 years after registration showed a small advantage to Finland for localised carcinomas and for the first two years for non-localised carcinomas only (Figure).

Table 2 Five-year observed survival rates by extent of the disease

\begin{tabular}{lll}
\hline Extent & Finland & South Wales \\
\hline Carcinoma-in-situ & 97 & 96 \\
Localised invasive & 66 & 63 \\
Non-localised & 29 & 31 \\
\hline
\end{tabular}

The expected length of life for patients with cervical cancer was calculated by stage of the disease (Table 3). The life expectancy for patients with carcinoma-in-situ was close to that of a comparable normal population free of the disease. The expected length of life for patients with non-localised disease was also similar in Finland and South Wales. However, for localised disease there was a difference between the countries; the loss of life expectancy in Finland was $15 \%$ but in South Wales it was 33\%. 
Table 3 Mean age at diagnosis, expected length of life for patients and for normal population, and loss in life expectancy due to the disease by the stage at diagnosis

\begin{tabular}{|c|c|c|c|c|c|}
\hline \multirow[b]{2}{*}{ Stage at diagnosis } & \multirow[b]{2}{*}{$\begin{array}{l}\text { Mean age at } \\
\text { diagnosis }\end{array}$} & \multicolumn{2}{|c|}{ Expected length of life } & \multicolumn{2}{|c|}{ Loss in life expectancy } \\
\hline & & Patients & $\begin{array}{l}\text { Normal } \\
\text { population }\end{array}$ & Years & (\%) \\
\hline \multicolumn{6}{|l|}{ FINLAND } \\
\hline Carcinoma-in-situ & 44 & 33 & 32 & -1 & $(-3)$ \\
\hline Localised & 52 & 21 & 25 & 4 & (15) \\
\hline Non-localised & 58 & 7 & 20 & 13 & (64) \\
\hline \multicolumn{6}{|l|}{ SOUTH WALES } \\
\hline Carcinoma-in-situ & 42 & 35 & 36 & 1 & (3) \\
\hline Localised & 51 & 18 & 27 & 9 & (33) \\
\hline Non-localised: & 56 & 8 & 23 & 14 & (63) \\
\hline Stage II & 54 & 13 & 24 & 11 & (48) \\
\hline Stage III & 58 & 4 & 21 & 17 & (80) \\
\hline Stage IV & 59 & 2 & 20 & 18 & (92) \\
\hline
\end{tabular}

Table 4 Number and percentage of cases of invasive cervical cancer by type of treatment

\begin{tabular}{|c|c|c|c|c|c|c|c|c|}
\hline \multirow[b]{3}{*}{ Treatment } & \multicolumn{4}{|c|}{ Localised } & \multicolumn{4}{|c|}{ Non-localised } \\
\hline & \multicolumn{2}{|c|}{ Finland } & \multicolumn{2}{|c|}{ South Wales } & \multicolumn{2}{|c|}{ Finland } & \multicolumn{2}{|c|}{ South Wales } \\
\hline & No. & $\%$ & No. & $\%$ & No. & $\%$ & No. & $\%$ \\
\hline Surgery & 266 & (10) & 60 & (16) & 32 & ( 3 ) & 54 & ( 5) \\
\hline Radiotherapy & 1796 & (64) & 185 & (50) & 704 & (72) & 667 & (63) \\
\hline Combined & 683 & (24) & 121 & (33) & 137 & (14) & 234 & (22) \\
\hline Other and none & 42 & ( 2$)$ & 3 & ( 1$)$ & 107 & (11) & 101 & (10) \\
\hline TOTAL & 2787 & $(100)$ & 369 & $(100)$ & 980 & $(100)$ & 1056 & $(100)$ \\
\hline
\end{tabular}

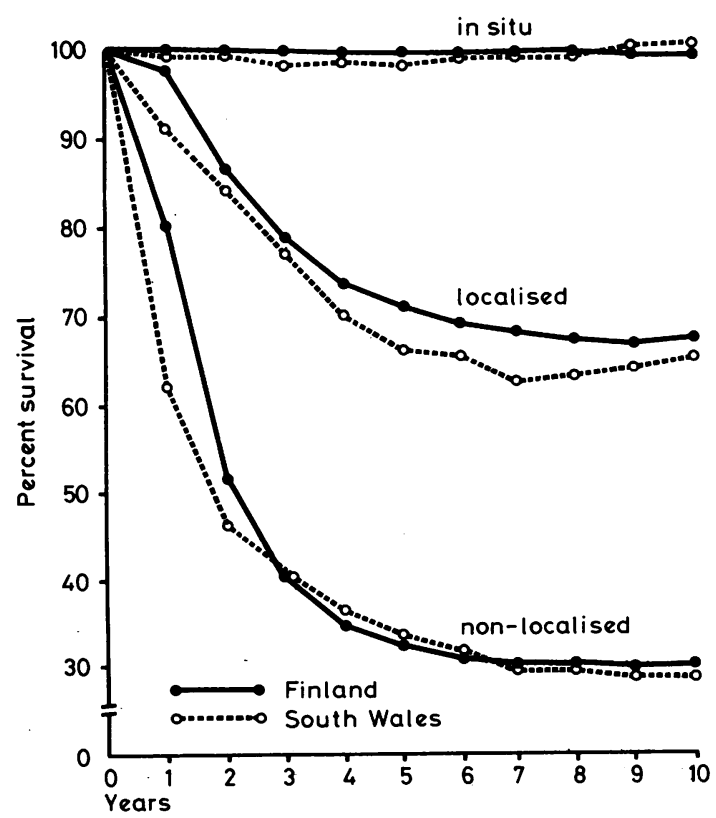

Figure Relative survival rates for carcinoma-in-situ and for localised and non-localised invasive carcinoma

(Finland and South Wales 1960-69, followed up to 1975).
The mean age at diagnosis for patients with localised carcinoma was eight or nine years greater than for those with a carcinoma-in-situ and the mean age at diagnosis for those with non-localised carcinoma was five or six years greater again (Table 3 ). In Finland the mean ages were one to two years higher than in South Wales for all three stages.

The distribution of treatments in the two countries was similar (Table 4). Radiotherapy alone was the most common treatment and it was given slightly more frequently in Finland than in South Wales.

The delay from the time of first symptoms to the time of treatment ranged from three to 10 months in different subgroups of patients by country and stage of disease (Table 5). The delay did not show any consistent association with the stage of disease: the

Table 5 Mean delay from time of first symptoms to time of treatment by extent of disease (sample analysis)

\begin{tabular}{cccccc}
\hline & \multicolumn{2}{l}{ Finland } & & & \multicolumn{2}{l}{ South Wales } \\
\cline { 2 - 3 } \cline { 5 - 6 } \cline { 5 - 6 } & No. & $\begin{array}{l}\text { Delay } \\
\text { (months) }\end{array}$ & & No. & $\begin{array}{l}\text { Delay } \\
\text { (months) }\end{array}$ \\
\hline Carcinoma-in-situ & 23 & 5 & & 19 & 5 \\
Localised & 21 & 3 & & 18 & 10 \\
$\quad$ Stage II & 19 & 4 & & 30 & 4 \\
Stage III-IV & 23 & 7 & & 28 & 7 \\
\hline
\end{tabular}


minimum was found for Finnish women with localised cancer and the maximum for Welsh women also with localised cancer.

\section{Discussion}

The clinical stage at diagnosis depends partly on the malignancy of the lesion with which is associated the speed of growth, and partly on the delay between the first symptoms and confirmation of the diagnosis. The former is a characteristic of the tumour and/or the host whereas the latter is a characteristic of the host and/or the health care system. The former refers to the immunological and the latter to the behavioural characteristics of the host.

The delay can be affected by an individual or by the health care organisation via the timing of the diagnosis, which in turn affects the results of treatment. In contrast, the speed of tumour growth is a biological characteristic which cannot be influenced by an individual or by a health care organisation. Below we discuss details of the survival pattern by stage and by country which are due to delay from first symptoms to diagnosis (lead time) and to the differences in the biological host characteristics and malignancy of the tumour.

In both countries patients with carcinoma-in-situ lesions experience roughly the normal life expectancy. For clinical carcinomas of the cervix the average loss in the expected length of life after diagnosis of the disease is about $25 \%$ in Finland and about $55 \%$ in Wales. Patients with non-localised (stage II, III, and IV) cancer may expect to lose two-thirds of their remaining years in both countries. The loss of life expectancy for patients with localised cancer àt diagnosis was one-third in South Wales and one-sixth in Finland. Therefore, the difference in overall survival between the countries was due to both the poor survival among Welsh patients with localised disease at diagnosis and the high frequency of non-localised cases compared with Finnish women.

The number of in-situ carcinomas depends on the extent of screening in the population and on activity within the health care system. Screening was practised more in Finland than in South Wales. ${ }^{9} 10$ The more unfavourable distribution by stage of clinical carcinomas in Wales can be partly ascribed to the differences in the population distribution by age $^{89}$; because the mean age of the total female population in Wales is higher than in Finland and because stage of disease and age are positively correlated.

The possibility remains that some of the differences are due to differences in definitions, coding, and other medical practices between the countries. However, the mean ages at diagnosis in this study were consistently only one to two years higher in Finland than in South Wales in all clinical stages, supporting the idea that such differences are of minor importance and that the definitions are essentially the same. Also, it is unlikely that the differences in survival (differences in the results of treatment) between the countries are due to the mode of treatment itself, because the distributions of patients by treatment were similar in the two countries.

Because the relative survival for cervical cancer is almost independent of age within four clinical stage groups, ${ }^{11}$ age is not a confounding factor after stratification by clinical stage. The differences in the mean ages at diagnosis were eight years (Finland) or nine years (South Wales) between in-situ carcinomas and localised carcinomas, and six years (Finland) or five years (South Wales) between localised and non-localised.. If the difference in mean age of patients with localised and non-localised tumour at diagnosis would be an indication of patient delay only, we arrive at an estimate of several years of delay. By contrast the delay in seeking medical treatment was less than one year and did not materially correlate with the extent of the disease when estimated in terms of the duration of symptoms reported to the registries from medical histories of the patients. Even if the estimates of patient delay from three to 10 months were based on small samples, it is unlikely that patient delay could really be of the order of five years, the difference of mean ages by stage.

From the observations between the countries and between the clinical stages we find as follows. Firstly, for patients with localised cancer the survival is better in Finland than in South Wales and the mean delay between first symptoms and initiation. of treatment is shorter in Finland than in Wales. The latter observation is based on small samples, but it is in agreement with the observations on survival rates. Secondly, non-localised tumours are diagnosed in women older than those with localised tumours. This difference yields the estimate of five to six years for the lead time (localised tumour to non-localised tumour). However, the data on delay between first symptom and initiation of treatment yields an estimate of lead time (preclinical disease to clinical cancer) for both localised and non-localised cases of less than a year.

The first of these observations fits the basic model of the natural history of cervical cancer. ${ }^{1}$ However, the second observation favours the hypothesis proposed by Ashley, ${ }^{2}$ according to which there are at least two forms of cervical cancer distinguished by age of appearance and speed of growth. There is no 
evidence that delay by Welsh patients with localised disease resulted in progress of localised to non-localised cancer, because tumours with long duration of symptoms were still localised at diagnosis. This further supports the hypothesis that localised tumours are slow growing ones. Finnish women may react more rapidly than the Welsh to mild and non-specific symptoms of slow growing tumours. In summary, population differences in age structure, delay between first symptoms and diagnosis, and differences in the biological characteristics of the disease are likely to account for the difference in survival between Finland and Wales. The natural history of cervical cancer may be more complicated than that of several other epithelial tumours, for which the speed of growth and the age of the patient are seldom correlated.

This study was carried out when R.W. was visiting scientist at the Department of Public Health, University of Tampere. M.H. was supported in part by the Finnish Foundation for Cancer Research.

Reprints from Matti Hakama, The Finnish Cancer Registry, Liisankatu 21B, SF-00170, Helsinki 17, Finland.

\section{References}

${ }^{1}$ Dunn JE Jr. The relationship between carcinoma in situ and invasive cervical cancer. Cancer 1953; 6: 873-886.

Ashley DJ. The biological status of carcinoma in situ of the uterine cervix. Br J Obstet Gynaecol 1966; 73: 372-381.

${ }^{3}$ Kottmeier HL, Kolstad P, eds. Annual report on the results of treatment in carcinoma of the uterus, vagina, and ovary. Sixteenth volume. Statements of results obtained in 1959 to 1968 inclusive. Stockholm: Pogo Print, 1976.

${ }^{4}$ Cutler SJ, Ederer F. Maximum utilisation of the life table method in analysing survival. J Chronic Dis 1958; 8: 699-712.

${ }^{5}$ Ederer F, Axtell LM, Cutler SJ. The relative survival rate: a statistical methodology. Natl Cancer Inst Monog 1961; 6: 101-21.

${ }^{6}$ Hakama M, Hakulinen T. Estimating the expectation of life in cancer survival studies with incomplete follow-up information. J Chronic Dis 1977; 30: 585-597.

${ }^{7}$ West RR. Cervical cancer: age at registration and age at death. Br J Cancer 1977; 35: 236-241.

${ }^{8}$ Teppo L, Hakama M, Hakulinen T, Lehtonen M, Saxén E. Cancer in Finland 1953-70: incidence, mortality, and prevalence. Acta Pathol Microbiol Scand 1975; Supplement 252.

${ }^{9}$ West RR. Cancer Registration in South Wales 1964-68. Cardiff: Welsh Hospital Board, 1974.

${ }^{10}$ Hakama M, Joutsenlahti U, Virtanen A, RäsänenVirtanen U. Mass screenings for cervical cancer in Finland, 1963-71. Organisation, extent, and epidemiological implications. Ann Clin Res 1975; 7: 101-11.

${ }^{11}$ The Cancer Registry of Norway. Survival of cancer patients. Cases diagnosed in Norway 1953-1967. Oslo: The Norwegian Cancer Society, 1975. 